\title{
Insights on the carbon mineralization potential of alteration minerals
}

\author{
CHIARA MARIENI ${ }^{1}$, MARTIN VOIGT ${ }^{2}$, GIUSEPPE \\ SALDI $^{1}$, PASCALE BÉNÉZETH ${ }^{1}$ AND ERIC H. OELKERS ${ }^{1}$ \\ ${ }^{1}$ Géosciences Environnement Toulouse-CNRS \\ ${ }^{2}$ Institute of Earth Sciences, University of Iceland \\ Presenting Author: chiara.marieni@get.omp.eu
}

In the past few decades, relatively fresh mafic and ultramafic rocks and minerals have been studied as potential geologic carbon storage hosts due to their high reactivity and widespread distribution. However, many reservoirs are characterized by different degrees of alteration, which leads to the presence of a suite of secondary minerals. The goal of this study is to assess if such phases can be considered as cation sources for carbon mineralization processes, and how their potential compares to that of primary minerals.

A series of laboratory carbonation experiments, as well as reaction path modelling, were conducted over the $\mathrm{pH}$ range 3-10 and at temperatures up to $200{ }^{\circ} \mathrm{C}$, as a function of $\mathrm{pCO}_{2}$. Experiments were performed in open and mixed-flow reactors to quantify the extent of the carbon mineralization process in the presence of alteration phases such as epidote, brucite, serpentine, and tremolite. The choice of these minerals is based on detailed consideration of naturally altered rocks. Reaction path models were then used to extrapolate the laboratory results to field scale and longer time frames.

Preliminary results suggest that many of the studied secondary phases can provide divalent cations and be carbonated as efficiently as primary phases, such as basaltic glass. Particular attention was paid to the initial composition of all the minerals during the assessment of their carbonation potential, highlighting the role of Ca-bearing compared to that of $\mathrm{Mg}$-bearing phases.

Overall, the findings of this study demonstrate that altered mafic and ultramafic rocks offer the potential for vast quantities of subsurface mineral storage worldwide. 